\title{
Osteopetrorickets: infantile malignant osteopetrosis paradoxically complicated by rickets
}

\author{
Deepa R. Biyyam • Stephen Done
}

Received: 11 June 2009 /Revised: 26 July 2009 /Accepted: 30 July 2009/Published online: 15 September 2009

(C) Springer-Verlag 2009

This 6-month-old girl presented with intermittent esotropia and a bulging fontanelle. CT head demonstrated significant thickening of the calvaria and facial bones. Subsequent radiographic skeletal survey revealed diffuse sclerotic bones with obliteration of the marrow cavity with a bonein-bone appearance in the small bones of the hands and feet, consistent with osteopetrosis. Additional findings included diffuse metaphyseal cupping and fraying, widening of the physes, and periosteal new bone formation along the long bones (Figs. 1 and 2). Radiographic features along

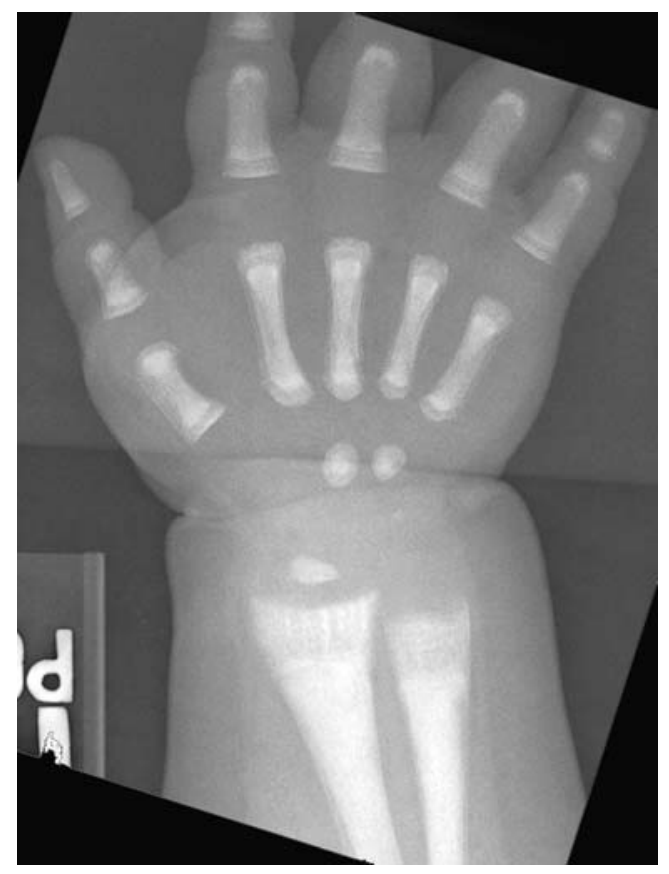

Fig. 1 AP view of the right wrist

\footnotetext{
D. R. Biyyam $(\bowtie) \cdot S$. Done

Department of Radiology, University of Washington,

Seattle Children's Hospital,

4800 Sand Point Way NE,

Seattle, WA 98105, USA

e-mail: deepa31@u.washington.edu
}

with clinical and biochemical findings were consistent with superimposed rickets.

Rickets is a paradoxical complication of infantile osteopetrosis resulting from inability of osteoclasts to maintain a normal calcium-phosphorus balance, despite markedly positive total body calcium. Bone marrow transplantation is the therapy of choice for osteopetrosis; however, the clinical response to bone marrow transplantation is inadequate if there is underlying rickets. Hence, it is important to detect and successfully treat rickets in these patients prior to bone marrow transplantation $[1,2]$.

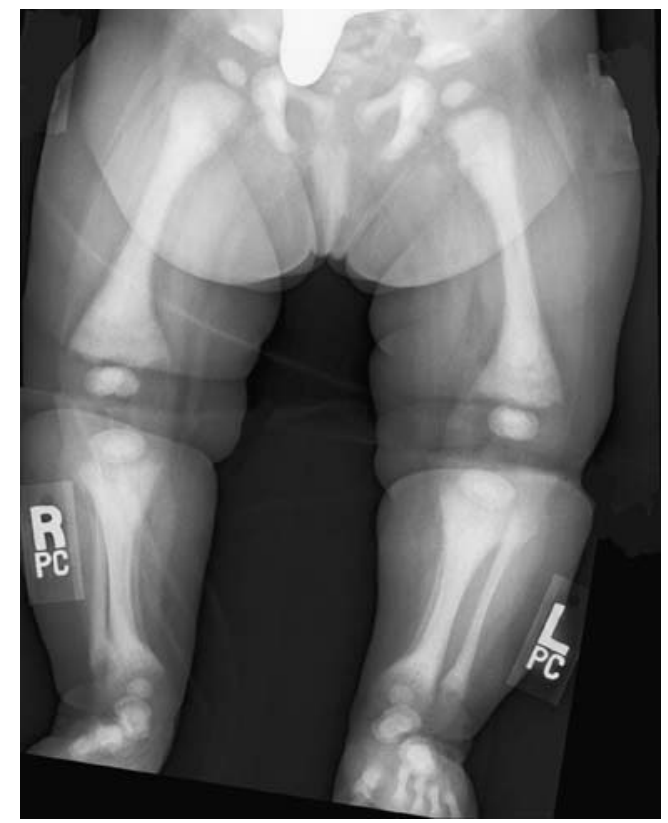

Fig. 2 AP view of lower extremities

\section{References}

1. Kaplan FS, August CS, Fallon MD et al (1993) Osteopetrorickets: the paradox of plenty, pathophysiology and treatment. Clinical Orthop 294:64-78

2. Donnelly LF, Johnson JF III, Benzing G (1995) Infantile osteopetrosis complicated by rickets. AJR 164:968-970 